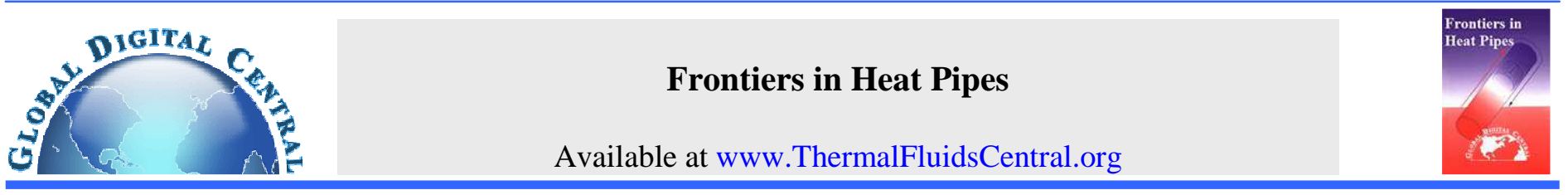

\title{
ULTRA THIN HEAT PIPE AND ITS APPLICATION
}

\author{
Hirofumi Aoki ${ }^{*}$ Masami Ikeda and Yuichi Kimura \\ Furukawa Electric Co., Ltd., Higashi-yawata 5-1-9, Hiratsuka, Kanagawa, 254-0016, Japan
}

\begin{abstract}
We have developed ultra thin heat pipe which can be applied to thinner and lighter electronic equipments. In this study, we focused on optimizing vapor and liquid flow pressure drop in the heat pipe. As a result, we have succeeded in developing 1 mm thickness heat pipe which had maximum heat transfer rate of $22.1 \mathrm{~W}$. And also, we have developed ultra thin heat pipe which had both high maximum heat transfer rate and thin thickness by optimizing inner structure. In this paper, we reported development of ultra thin heat pipe and some applications of it.
\end{abstract}

Keywords: Ultra Thin Heat Pipe, Maximum Heat Transfer Rate, Thermal Resistance, Thermal Solution

\section{INTRODUCTION}

Recently, most electronic equipments tends to be thinner and lighter, so heat pipe, which is used in thermal solution to cool down heat source such as semiconductor device, needs to be thinner and lighter too. But heat pipe has unfavorable feature that thermal performance becomes worse when heat pipe is flattened. When heat pipe is flattened, pressure drop originated in vapor and liquid flow are increased remarkably because of narrow space for vapor and liquid flow. So heat pipe does not work when inner pressure drop cross over capillary force of wick structure. Therefore, in order to realize heat pipe which has both thin thickness and high performance, optimization of inner structure is needed. Figure 1 shows relationship of maximum heat transfer rate and heat pipe thickness. The maximum heat transfer rate of conventional groove heat pipe is shown in hutched area. Groove heat pipe has high maximum heat transfer rate when heat pipe thickness is more than $3 \mathrm{~mm}$. However, when heat pipe thickness is $2 \mathrm{~mm}$ or less than, the maximum heat transfer rate drops to almost zero. In order to overcome this problem, we utilize mesh wick, which is optimized by theoretical calculation, and the container with thin wall thickness. Then, we have developed the ultra thin heat pipe, shown by dotted area in Fig.1, which has high maximum heat transfer rate.

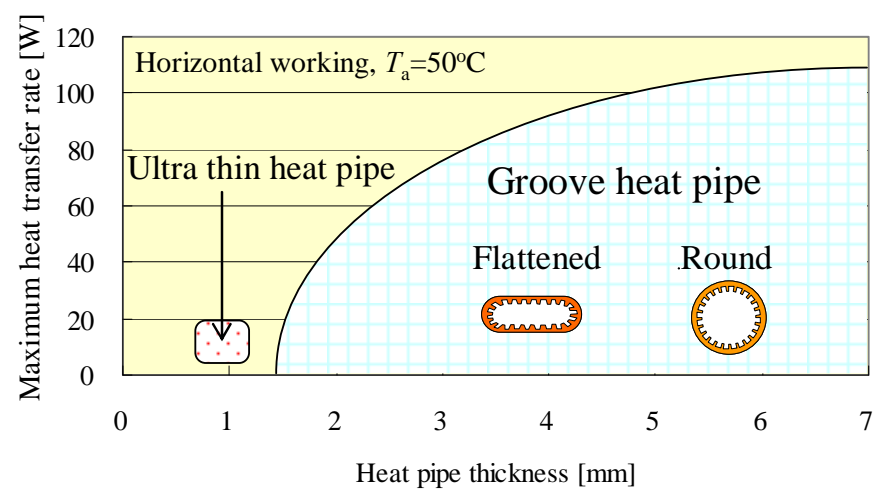

Fig. 1 Heat Pipe thickness dependence of maximum heat transfer rate

\section{THEORETICAL STUDY OF THIN HEAT PIPE}

\subsection{Pressure balance in heat pipe}

Heat pipe for common use consists of copper container, deionized water as working liquid, and wick structure. There are several types of wick such as groove, sintered metal, wire, and mesh, which are selected depending on specification. Though groove wick is widely used because of its simple structure and high reliability, it is unfavorable for thin heat pipe since capillary force of it is very small. In order for thin heat pipe to operate normally, the capillary force $\Delta P_{\mathrm{c}}$ should be larger than total pressure drop in heat pipe. Though there are several kinds of pressure drop in heat pipe, it is vapor flow pressure drop $\Delta P_{\mathrm{v}}$ and liquid flow pressure drop $\Delta P_{1}$ that determine thermal performance of heat pipe mainly.

Thus, formula (1) is approved.

$$
\Delta P_{\mathrm{c}} \geq \Delta P_{\mathrm{v}}+\Delta P_{1}
$$

If this inequality is not satisfied, working liquid cannot return to evaporator section from condenser section and then dry-out will occur. In case of thin heat pipe, both vapor and liquid flow pressure drop become larger because their flow channels are restricted. Figure 2 shows inner structure of flattened heat pipe. In such structure, cross section of vapor channel approaches to rectangle, then vapor flow pressure drop is expressed by next equation.

$$
\Delta P_{\mathrm{v}}=\frac{12 \mu_{\mathrm{v}} Q}{\rho_{\mathrm{v}} a b D^{2} \lambda(1+s)^{2}\left(1-\frac{48 s}{\pi^{5}} \times 4 \tanh \frac{\pi}{2 s}\right)} L_{\text {eff }}
$$

On the other hand, $\Delta P_{1}$ is decided by permeability of wick, according to Darcy's law.

$$
\Delta P_{1}=\frac{\mu_{1} Q}{K A_{\mathrm{w}} \rho_{1} \lambda} L_{\text {eff }}
$$

Then, we tried to develop ultra thin heat pipe by optimizing both vapor and liquid channel in order to minimize total of vapor and liquid pressure drop.

\footnotetext{
* Corresponding author. Email: aoki.hirofumi@furukawa.co.jp
} 


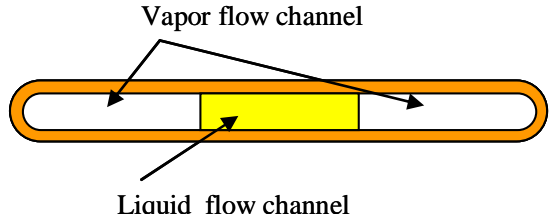

Liquid flow channel

Fig. 2 Inner structure of flattened heat pipe

\subsection{Optimization of thin heat pipe}

In this section, we show how to optimize inner structure of thin heat pipe. As mentioned above, because vapor and liquid pressure drop are very high in thin heat pipe, high capillary force is needed to drive working fluid circulations. Capillary force of wick structure is estimated by following formula.

$$
\Delta P_{\mathrm{c}}=\frac{2 \delta}{r_{\mathrm{c}}} \cos \theta
$$

Table 1 shows property of typical wicks which are commonly used. From table 1, we can say that groove wick is unfavorable for thin heat pipe because of low capillary force. Then, we consider improving thermal performance of heat pipe by using mesh wick or sintered metal wick.

Table 1 Property of typical wick structure

\begin{tabular}{|c|c|c|c|}
\hline & $r_{\mathrm{c}}[\mathrm{m}]$ & $\Delta P_{\mathrm{c}}[\mathrm{Pa}]$ & $K\left[\mathrm{~m}^{2}\right]$ \\
\hline $100 \mathrm{mesh}$ & $1.2 \times 10^{-4}$ & 892 & $1.8 \times 10^{-10}$ \\
\hline $200 \mathrm{mesh}$ & $6.3 \times 10^{-5}$ & 1700 & $5.5 \times 10^{-11}$ \\
\hline \multirow{2}{*}{ Sintered metal } & $1.0 \times 10^{-5}$ & 1070 & $1.0 \times 10^{-11}$ \\
& $-1.0 \times 10^{-4}$ & -10700 & $-1.0 \times 10^{-9}$ \\
\hline \multirow{2}{*}{ Groove } & $2.5 \times 10^{-4}$ & 71 & $3.5 \times 10^{-9}$ \\
& $-1.5 \times 10^{-3}$ & -428 & $-1.3 \times 10^{-7}$ \\
\hline
\end{tabular}

Though we mention that high capillary force is needed in previous section, it is not enough for thin heat pipe. When the effective pore radius of wick is reduced and then capillary force is increased, liquid flow pressure drop is increased because permeability is decreased. In this case, the maximum heat transfer rate is restricted by liquid flow pressure drop. From formula (3), it is needed that liquid flow channel is enlarged in order to reduce liquid flow pressure drop. However, when liquid flow channel is enlarged, vapor flow channel is narrowed and vapor flow pressure drop restricts thermal performance in turn. Therefore, it is necessary to consider the balance of vapor and liquid flow pressure drop. Fig. 3 shows dependence of wick width on the maximum heat transfer rate of sintered metal heat pipes whose thickness is $1 \mathrm{~mm}$ and length is $150 \mathrm{~mm}$. From Fig. 3, we can see that high capillary force does not always yield high performance.

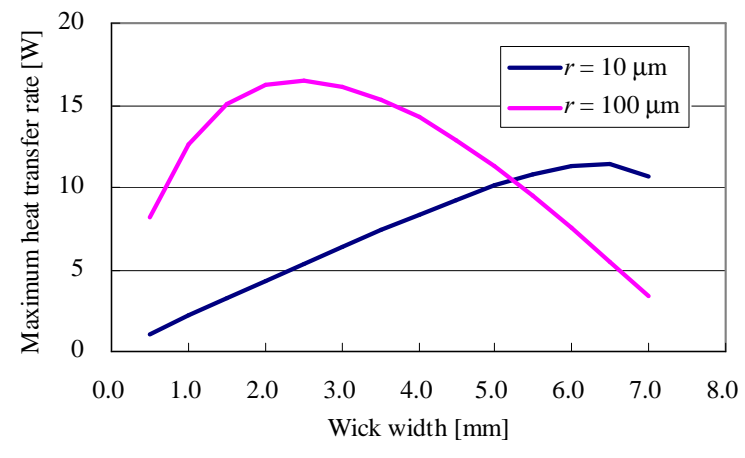

Fig. 3 Maximum heat transfer rate in various wick width. (sintered metal ; $r=10 \mu \mathrm{m}, 100 \mu \mathrm{m})$
Seeing this graph, it is found that $10 \mu \mathrm{m}$ and $100 \mu \mathrm{m}$ have different, position of peak and it depends on wick width which heat pipe has higher maximum heat transfer rate. This difference caused by pressure balance in heat pipes. So pressure balance normalized by capillary force in the heat pipes is shown in Fig.4.
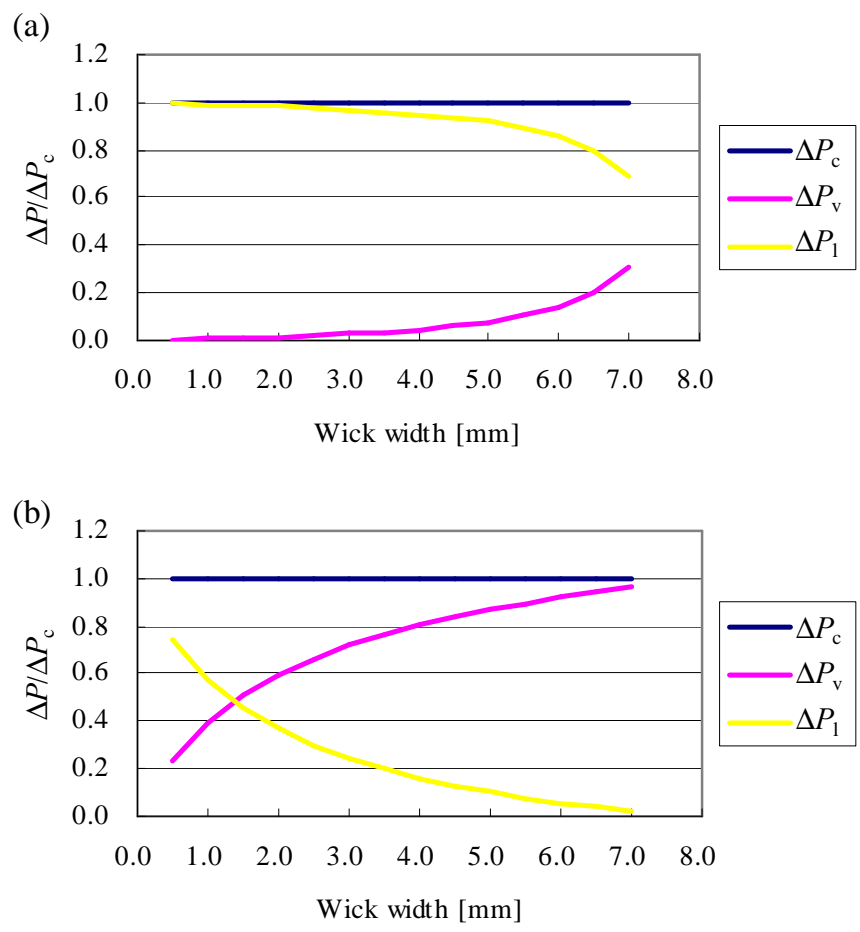

Fig. 4 Pressure balance normalized by capillary force in thin heat pipe. ((a) $r=10 \mu \mathrm{m},(\mathrm{b}) r=100 \mu \mathrm{m})$

As for $r=10 \mu \mathrm{m}$, influence of liquid flow pressure drop is very large because permeability is low. In this case, wick width is preferable to be larger in order to extend liquid flow channel. So, the peak of the maximum heat transfer rate exists in the side of large width. On the other hand, with respect to $r=100 \mu \mathrm{m}$, relationships between superior and inferior of liquid and vapor flow pressure drop change places depending on wick width. When wick width is narrow, liquid flow pressure drop is larger than vapor flow pressure drop. The opposite is approved too. In general, the former type of wick is preferable for thinner heat pipe, and the latter yields high performance in thicker heat pipe shown in Fig.5.

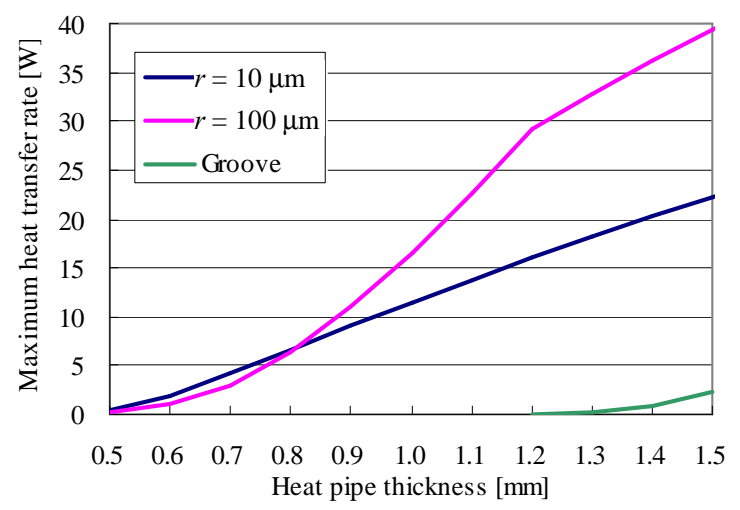

Fig. 5 Thickness dependence of maximum heat transfer rate in sintered metal wick heat pipe. 


\subsection{The maximum heat transfer rate of ultra thin heat pipe}

Considering from the above, we utilize mesh wick which has moderate capillary pressure head and moderate permeability for ultra thin heat pipe. Figure 6 shows theoretical value of maximum heat transfer rate in ultra thin heat pipe.

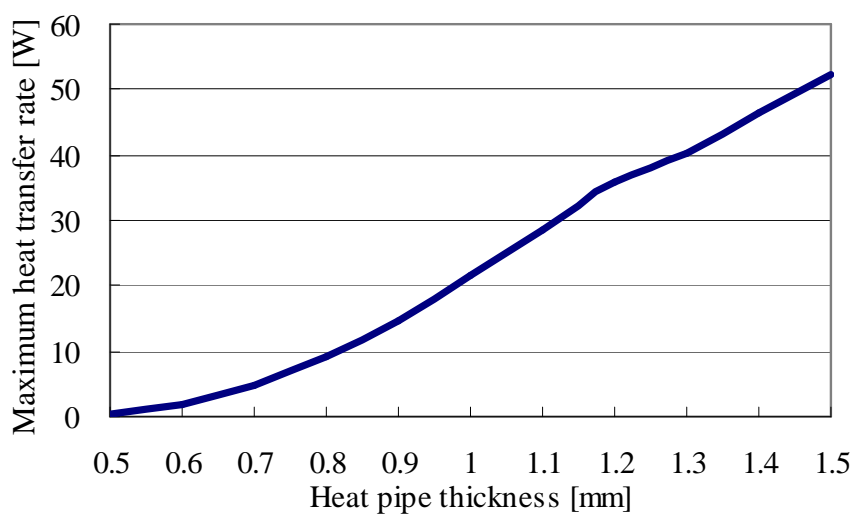

Fig. 6 Thickness dependence of maximum heat transfer rate in ultra thin heat pipe.

When heat pipe thickness is $1 \mathrm{~mm}$, maximum heat transfer rate is expected to be $21.4 \mathrm{~W}$.

\subsection{Thermal resistance of ultra thin heat pipe}

Thermal resistance is also important to evaluate thermal performance of heat pipe and it can be also expected theoretically. In this paper, only calculated result is shown in Fig. 7, because of space limitation.

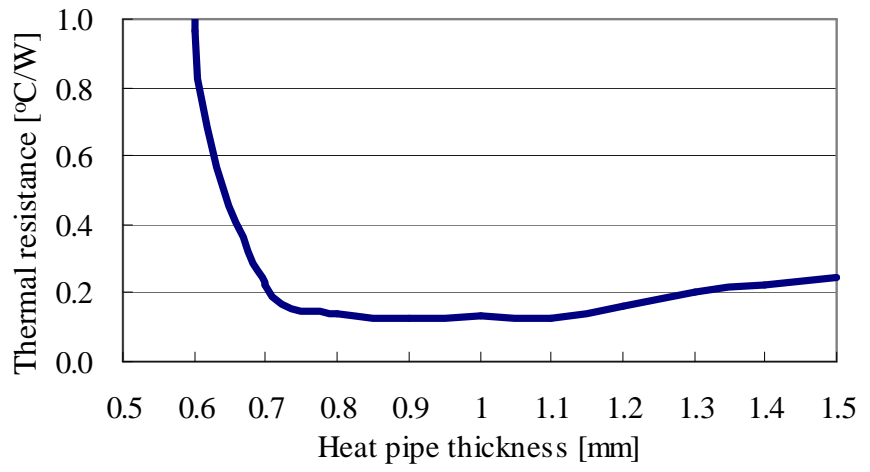

Fig. 7 Thermal resistance of ultra thin heat pipe (calculated value)

When heat pipe thickness is thinner, thermal resistance increases remarkably because vapor flow pressure drop becomes large excessively.

\section{EXPERIMENTAL EQUIPMENT AND PROCEDURE}

Experimental apparatus is shown in Fig. 8. Copper block heater was used for heat source whose size was $40 \mathrm{~mm} \times 10 \mathrm{~mm}$. For condenser section, copper block which was cooled by water cooling system was used. Condenser size was $85 \mathrm{~mm} \times 10 \mathrm{~mm}$. Heat pipe was attached to copper blocks at both evaporator and condenser section on contact with thermal grease.

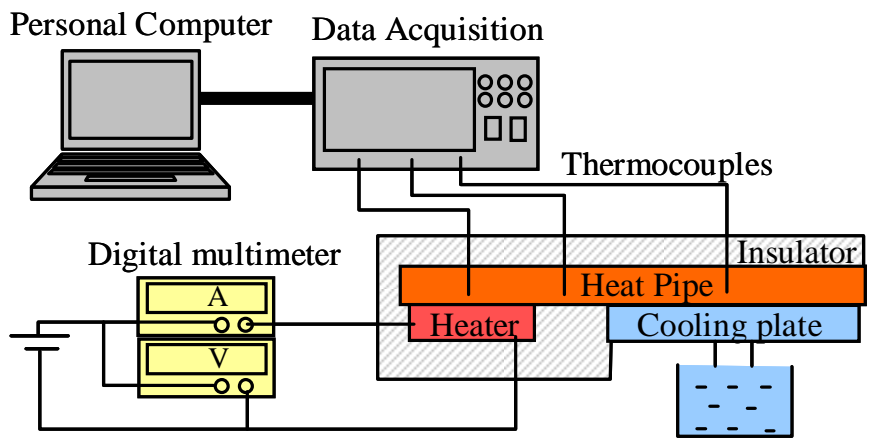

Water cooling system

Fig. 8 Schematic of experimental setup

Temperature distribution was measured by thermocouples. Fig. 9 shows thermocouples location on heat pipe. In addition, temperature of heater block was measured. For thermal performance test, temperature on adiabatic section was kept $50{ }^{\circ} \mathrm{C}$ and heat pipe was settled in horizontal position.

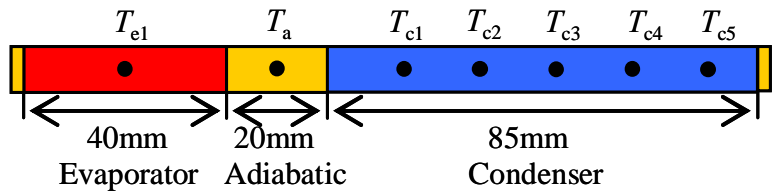

Fig. 9 Thermocouple Location

Experimental procedure of thermal performance test is given below.

1. Attach thermocouples to heat pipe.

2. Attach heat pipe to copper blocks of both evaporator and condenser section on contact with thermal grease.

3. Clamp heat pipe on copper blocks and adjust test fixture of heat pipe to required angle.

4. Turn on power of heater and water cooling system and record temperature of all thermocouples.

5. Adjust water temperature so that adiabatic temperature will be 50 ${ }^{\circ} \mathrm{C}$.

6. Wait until each temperature reach steady state and record temperature which is averaged for the last 5 minutes.

7. Increase heat load and repeat procedure 4 to 6 until dry-out is occurred.

From obtained result, the maximum heat transfer rate and thermal resistance will be known. Here, thermal resistance of evaporator $R_{\mathrm{e}-\mathrm{a}}$, and heat pipe $R_{\mathrm{hp}}$ is defined as below equations.

$$
\begin{aligned}
& R_{\mathrm{e}-\mathrm{a}}=\left(T_{\mathrm{e}}-T_{\mathrm{a}}\right) / Q \\
& R_{\mathrm{hp}}=\left(T_{\mathrm{e}}-T_{\mathrm{c}}\right) / Q
\end{aligned}
$$

When dry-out is occurred in heat pipe, $R_{\mathrm{e}-\mathrm{a}}$ will increase suddenly. We defin themaximum heat transfer rate as adjacent heat input at which dry-out is occurred.

\section{RESULT AND DISCUSSION}

\subsection{Thermal performance of ultra thin heat pipe}

Figure 10 shows thermal performance of ultra thin heat pipe whose thickness is $1 \mathrm{~mm}$ and length is $150 \mathrm{~mm}$. As diagram indicates, maximum heat transfer rate is $22.5 \mathrm{~W}$ and thermal resistance of heat pipe is $0.13{ }^{\circ} \mathrm{C} / \mathrm{W}$. We can confirm that experimental result agrees with calculation well (Fig.6 and Fig. 7). 
(a)

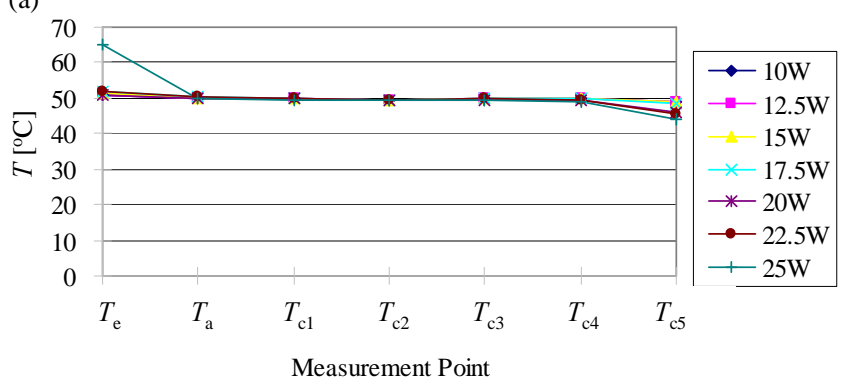

(b)

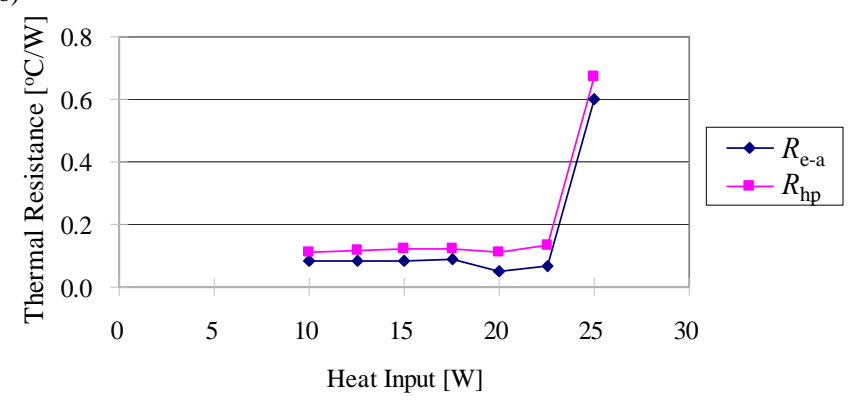

Fig. 10 Thermal performance of ultra thin heat pipe. (a)temperature distribution, (b)thermal resistance

In order to adopt ultra thin heat pipe to electronic equipment, it is necessary to have bended section. In the present, the minimum bending radius is $25 \mathrm{~mm}$, which thermal performance degradation is not found. So, ultra thin heat pipe can be applied to most of thermal solutions in electronic equipments.

Figure 11 shows the maximum heat transfer rate of ultra thin heat pipe in various thicknesses. In the area where thickness is $1 \mathrm{~mm}$ or less, experimental value and calculated value are corresponding well. However, there is about $20 \%$ error margin in these values at $1.5 \mathrm{~mm}$ thickness. The reason why is that vapor flow channel is approximated to rectangle when vapor flow pressure drop is calculated by formula (2), though vapor flow channel geometry at $1.5 \mathrm{~mm}$ thickness goes away from rectangle shape. Then, the error margin comes into being. Therefore, it is necessary to calculate vapor flow pressure drop by other methods in such area.

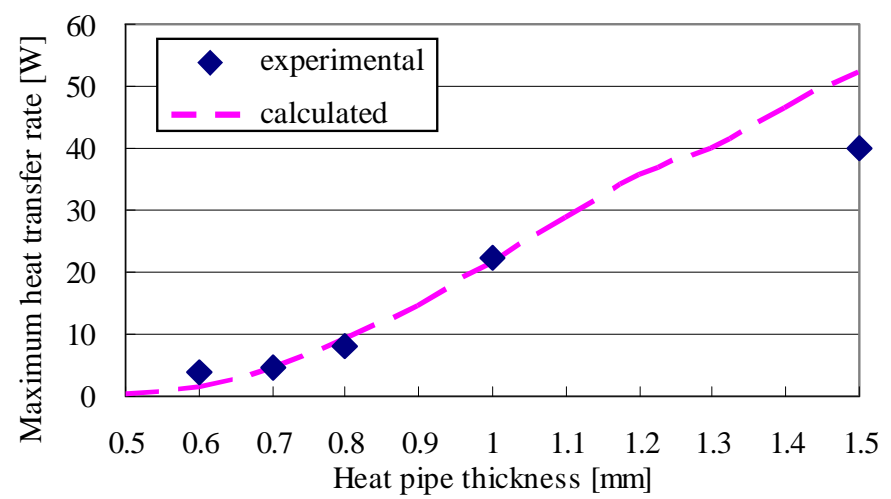

Fig. 11 Maximum heat transfer rate of ultra thin heat pipe in various thickness

\subsection{Application of ultra thin heat pipe}

In this section, some applications of ultra thin heat pipe are introduced.

Figure 12 shows an application of remote heat sink. The heat sink consists of $1 \mathrm{~mm}$ thickness heat pipe, $0.5 \mathrm{~mm}$ thickness attach plates and $5 \mathrm{~mm}$ height fin units, so maximum thickness of this heat sink is only $6 \mathrm{~mm}$. All parts of heat sink are soldered.

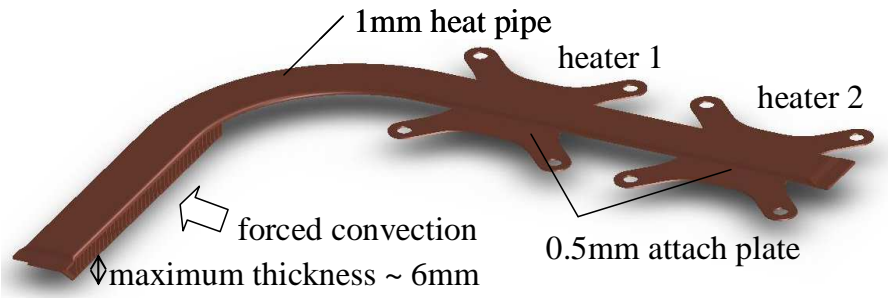

Fig. 12 Remote heat sink apparatus

In this experiment, two heat sources are attached to each attach plates with thermal grease. And Fin units are cooled by centrifugal fan (not illustrated) on condition that fan voltage is constant. Measurement is conducted in open air and same heat input is added to each heat source from $3 \mathrm{~W}$ to $13.5 \mathrm{~W}$. In that condition, thermal resistance between heat sources and room temperature is measured.

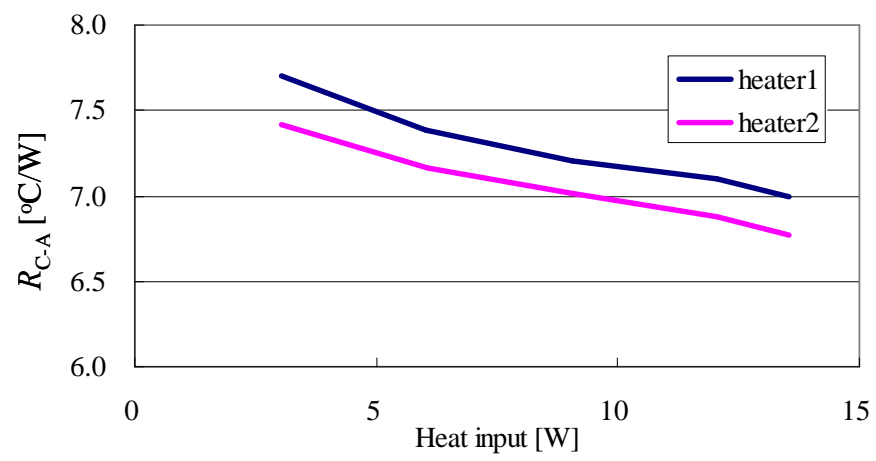

Fig. 13 Experimental result of remote heat sink

Experimental result of remote heat sink is shown in Fig. 13. We can see that heat pipe works normally in the experiment and dry-out does not occur up to total $27 \mathrm{~W}$. Here, maximum heat transfer rate of this heat sink is more than the value which is shown in last section, because effective length of heat pipe is shorter and working temperature is larger than $50^{\circ} \mathrm{C}$. Thus, ultra thin heat pipe can be used for remote heat sink whose thickness needs to be thin such as mobile PC.

Next, we introduce another application of ultra thin heat pipe as heat spreader [5]. Figure 14 shows manufactured heat sink which consists of $0.8 \mathrm{~mm}$ thickness heat pipe and $0.2 \mathrm{~mm}$ thickness nickel plated aluminum plate. These parts are soldered for assembly.

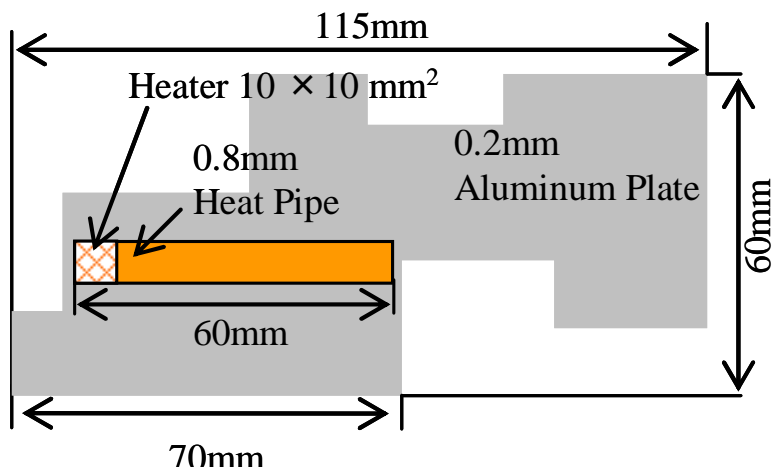

Fig. 14 Heat spreader apparatus

We compare the heat sink and $0.3 \mathrm{~mm}$ thickness graphite sheet which has same shape. Ceramic heater is used for heat source and attached onto heat pipe or graphite sheet directly with thermal grease. Then, we measure temperature distribution of heat spreaders. Figure 15 shows experimental results on condition that heat input is $5 \mathrm{~W}$ and cooling method is natural convection. We can see that heat sink suppressed heat spot better than graphite sheet and lower heat source temperature by 17 ${ }^{\circ} \mathrm{C}$. 

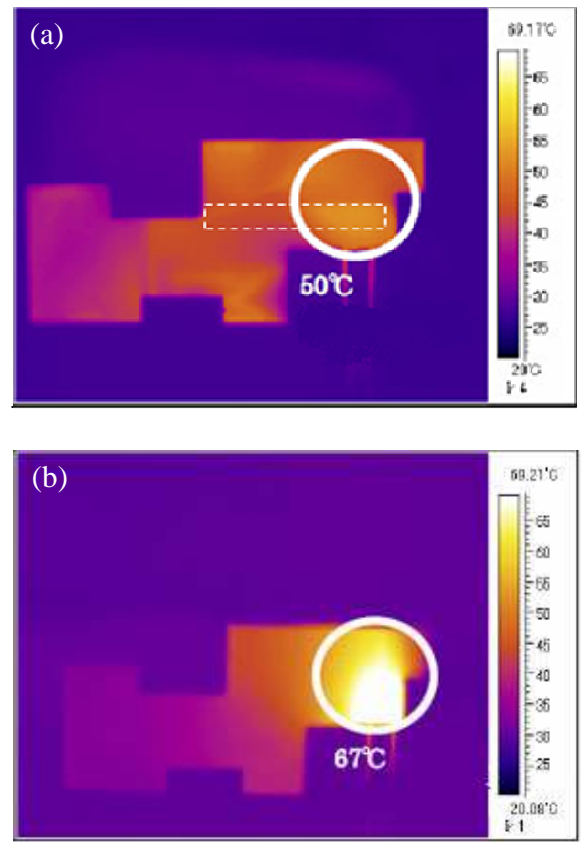

Fig. 15 Temperature distribution of heat sinks

(a) heat pipe + aluminum plate (b) graphite sheet

From what has been discussed above, we can conclude that ultra thin heat pipe can be applied to various thermal solutions, such as remote heat sink and heat spreader, etc., which is demanded to be thin for mounting to electronic equipments.

\section{CONCLUSIONS}

Theoretical study and experimental research of ultra thin heat pipe is done. Conclusion of this paper is as follows.

1. We have developed ultra thin heat pipe which has high maximum heat transfer rate by optimizing inner structure.

2. In the range which heat pipe thickness is $1 \mathrm{~mm}$ or less, experimental value and calculated value are corresponding well in thermal performance. But, it is necessary to improve calculation method of vapor flow pressure drop in the area where vapor flow channel geometry goes away from the rectangle.

3. Ultra thin heat pipe can be used for various thermal solutions whose thickness is needed to be thin.

\section{NOMENCLATURE}

$A_{\text {eva }} \quad$ area of evaporator section $\left[\mathrm{m}^{2}\right]$

$A_{\mathrm{w}} \quad$ area of wick cross section $\left[\mathrm{m}^{2}\right]$

$D \quad$ Hydraulic diameter [m]

$K \quad$ Permeability $\left[\mathrm{m}^{2}\right]$

$L_{\text {eff }} \quad$ effective length [m]

$Q \quad$ heat input [W]

$r_{\mathrm{c}} \quad$ effective pore radius [m]

$R_{\mathrm{e}-\mathrm{a}} \quad$ thermal resistance between evaporator and adiabatic section $\left[{ }^{\circ} \mathrm{C} / \mathrm{W}\right.$ ]

$R_{\mathrm{hp}} \quad$ thermal resistance of heat pipe [ $\left.{ }^{\mathrm{c}} \mathrm{C} / \mathrm{W}\right]$

$S \quad$ aspect ratio

$T_{\mathrm{a}} \quad$ temperature of adiabatic section $\left[{ }^{\circ} \mathrm{C}\right]$

$T_{\mathrm{c}} \quad$ temperature of condenser section $\left[{ }^{\circ} \mathrm{C}\right]$

$T_{\mathrm{e}} \quad$ temperature of evaporator section $\left[{ }^{\circ} \mathrm{C}\right]$

$\delta \quad$ surface tension $[\mathrm{N} / \mathrm{m}]$

$\Delta P_{\mathrm{c}} \quad$ capillary force $[\mathrm{Pa}]$

$\Delta P_{1} \quad$ liquid flow pressure drop [Pa]

$\Delta P_{\mathrm{v}} \quad$ vapor floe pressure drop $[\mathrm{Pa}]$

$\lambda \quad$ latent heat of evaporation

$\mu_{\mathrm{v}} \quad$ absolute viscosity of vapor $\left[\mathrm{Ns} / \mathrm{m}^{2}\right]$

$\mu_{1} \quad$ absolute viscosity of liquid $\left[\mathrm{Ns} / \mathrm{m}^{2}\right]$

$\rho_{\mathrm{v}} \quad$ density of vapor $\left[\mathrm{kg} / \mathrm{m}^{3}\right]$

$\rho_{1} \quad$ density of liquid $\left[\mathrm{kg} / \mathrm{m}^{3}\right]$

$\theta \quad$ contact angle $\left[{ }^{\circ}\right]$

\section{REFERENCES}

Masafumi Katsuta, Tomoya Shindo, Koichiro Saito, Junji Sotani, Yuichi Kimura and Yoshio Nakamura, "Heat transfer steady and transient characteristics in flat palate micro heat pipe", Proceedings of the 13th International Heat Pipe Conference, 360, 2004.

Bienert, W. B. and Skrabek, E. A. "Heat Pipe Design Handbook", Contract Rept. No.NAS9-11927, 1972.

Seo, J. K., "A generalized mathematical model to account for the effect of liquid-vapor international shear stress of a heat pipe with a groove wick structure: modified shah method", Proceedings of the 7th International Heat Pipe Symposium, 2003.

Ohshima K., Matsushita T., and Murakami M., Hear Pipe Engineering, Asakura Shoten Ltd., 1981 (in Japanese).

Furukawa Electric News release, "Launch of a Heat Sink Using the World's Thinnest Heat Pipe $800 \mu \mathrm{m}$ in Thickness", July 1, 2009. 